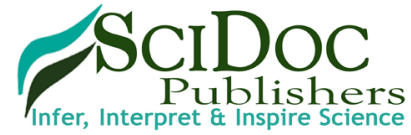

\section{Factors Affecting Utilization of Cervical Cancer Screening Services among Nurses in a Teaching Hospital in Ibadan, Nigeria}

Akinpelu $\mathrm{AO}^{1}$, Agboola $\mathrm{OA}^{2}$, Umezurike $\mathrm{ET}^{2 *}$

${ }^{1}$ Health Management and Information Science, Lead City University, Ibadan, Oyo, Nigeria.

${ }^{2}$ Microbiology, Lead City University Ibadan, Ibadan, Oyo, Nigeria.

\title{
Abstract
}

Invasive cervical cancer is the second-most common cancer in women world-wide, $80 \%$ of these cases were discovered through records to be from developing countries. It can be readily detected in the premalignant phase, cervical cancer remains one of the most common cancer in Nigeria and fifth in the United Kingdom [1]. As a developing country, Nigeria is also battling with cervical cancer as a health problem; Olaniyi (2010) [4] reported that cervical cancer is the commonest female cancer and is the leading cause of female death in Nigeria.

This descriptive and cross-sectional study was aimed at assessing and documenting factors affecting utilization of cervical cancer screening among Nurses in a teaching Hospital in Ibadan, Oyo state, Nigeria. A total of 180 questionnaires administered and retrieved from the nurses however only $177(98 \%)$ met criteria for analysis. Hence, the respondent rate was $98.0 \%$. The age of the respondent ranged from 23 to 59 years; the median age \pm standard deviation was $40 \pm 9.5$ years. Majority of respondents $101(57.1 \%)$ are afraid of cervical cancer screening procedure pain. Virtually all the respondents $140(79.1 \%)$ has the believed that they are healthy and that they cannot have cervical cancer. Also $115(65 \%)$ respondents were of the view that CCS does not consumes time $99(55.9 \%)$ respondents disagrees that CCS is not accessible. $148(41.8 \%)$ respondents disagrees with not been released by their husbands to go for CCS screening. Virtually all the respondents $149(42.1 \%)$ negates their culture being against CCS. $93(10.5 \%)$ respondents agrees that nurses do advocate for cervical cancer screening. There is no medical indication to go for cervical cancer screening $108(61.1 \%)$ of the respondents disagree with this factor. $125(70.6 \%)$ of the respondents opined that CCS money should be subsidized. The researchers within this study are of the opinion that rigorous health campaigns need to still be done as awareness and screening for this kind of cancer seems to be low. Nurses come in contact with patients on a daily basis and adequately sensitizing the nurses will go a long way in making the patients knowledgeable about this procedure and the benefits which accrue from undertaking this procedure.

Keywords: Cervical Cancer; Screening; Nurses; Pap Smear.

\section{Introduction}

Invasive cervical cancer is the second-most common cancer in women world-wide, $80 \%$ of these cases were discovered through records to be from developing countries. It can be readily detected in the premalignant phase, cervical cancer remains one of the most common cancer in Nigeria and fifth in the United Kingdom [1].

Internationally, cervical cancer has been regarded as the third most popular type of cancer among women asides breast and colorectal cancer this was reported by Al-Meer, Aseel, Al- Khalaf,
Al-Kuwari and Ismail (2009) [2]. Cervical cancer however has a preventable option using the cervical cancer smear screening programmes which has given effective reduction in mortality rate. The risk factors for cervical cancer include early age of sexual intercourse and multiple sexual partners. Also infection with human papiloma virus (HPV) increases the relative risk for developing cervical cancer.

The American preventive services task force recommended pap smear test at least every 3 years, it is however estimated that only $5 \%$ of women in the developing countries have screened for this diseases with pap smears compared to $40-50 \%$ in the developed

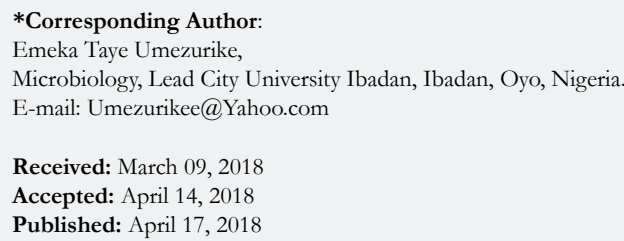

Copyright: Emeka Taye Umezurike ${ }^{\circ}$ 2018. This is an open-access article distributed under the terms of the Creative Commons Attribution License, which permits unrestricted use, distribution and reproduction in any medium, provided the original author and source are credited. 
countries. The possible poor utilization of cervical cancer screening may be attributed to poor communication between healthcare workers and patients regarding availability and benefits of the screening. In many of the developing countries women's knowledge of cervical cancer is very limited, Mupepi et al., (2011) [3] affirmed that vast majority of the women in some countries had not heard of cervical cancer screening.

As a developing country, Nigeria is also battling with cervical cancer as a health problem; Olaniyi (2010) [4] reported that cervical cancer is the commonest female cancer and is the leading cause of female death in Nigeria. Aliyu et al., (2013) [5] in their study reported that there is a common problem of women having a reactive attitude towards the disease and this appears to be prevalent in Pacific societies. According to Ahmed (2013) [5] the incidence of cervical cancer in Nigeria is 250/100,000 women. Another factor reported by Kahn (2010) [6] is that when women have participated in cervical cancer screening, about $5 \%$ of those diagnosed with abnormality in their results usually do not attend follow-up clinics for prompt management of what was discovered in their smear despite being adequately notified and booked for follow-up care.

Ana Bezerra, Alexandre and Bairro (2011) [7] opined that cervical cancer is a public health issue based on the high rates of prevalence and high rates of mortality in women most especially in low socioeconomic levels who are in the active productive phase of their lives. This indicates a strong relationship of this type of cancer with pre-cancerous living conditions like low indices of human development and absence or weakness of community education strategies (such as health promotion and prevention programs and several limitation factors hindering access to public health services for early diagnosis and treatment of precursor lesions).

\section{Statement of Problem and Objectives}

The researchers within this study opine that nurses serve as advocate for patient, family and the community at large; they are critical to healthcare system, improving the quality of human life around the clock twenty - four hours - a - day. Their influence, safety, quality and efficacy of care which they provide and the essential competencies are required to fulfil these responsibilities. Since nurses interphase with patients all the time, the researchers thought it wise to review factors which affect their use of cervical cancer screening. The goal being to identify these factors and then begin to advocate for ways to lower the influence of these factors. Nurses forms a core or great percentage of the health care team they health educate client and patient on the utilization of available facilities within and outside the hospital in order to maintain and promote optimal health. Yet according to Ahmed, Sabitu, Idris and Ahmed, (2013) [5] utilization of screening services among nurses is very low. It therefore interests the researcher to investigate the factors influencing the utilization of cervical cancer screening among the Nurses in Adeoyo Maternity Teaching Hospital Ibadan, Oyo State.

Research Question - What are the factors affecting utilization of cervical cancer screening among Nurses in Adeoyo Maternity Teaching Hospital?

\section{Research Design}

This descriptive and cross-sectional study was aimed at assessing and documenting factors affecting utilization of cervical cancer screening among Nurses in a teaching Hospital in Ibadan, Oyo state, Nigeria.

\section{Setting of Study}

The study was conducted in Adeoyo Maternity Teaching Hospital Ibadan, Nigeria.

\section{Target Population}

The study populations are professional Nurses working at Adeoyo Maternity Teaching Hospital Ibadan of which majority are females and in their reproductive age. The professional nurses' cadres ranged between staff nurse and chief nursing officer with total number over 204 nurses in the following units Adminstration department, Gynaecology ward, Labour room, Antenatal ward, Ante-natal clinic, Immunization, Family planning, Main \& minor theatres, Post cesarean section ward, Life saving scheme, SCBU, Sexually transmitted infection, Casuality, Tuberculosis clinic (TBL), Creche, Health education unit, CHOPD, NHIS, CNO's, Clinical instructor officer and Lying-in- ward.

\section{Sampling Procedure and Sample}

This is a descriptive and cross-sectional study aimed at assessing and documenting the awareness, perception and factors influencing cervical cancer screening among nurses working at Adeoyo Maternity Teaching Hospital using a validated structured questionnaire.

\section{Sampling Techniques}

Stratified, proportionate and simple random sampling techniques were adopted for the selection of the 180 nurses from a total of over 204 nurses from all cadres of nurses in the hospital. The sample is a subset of the total population which gives representation size of $88 \%$ of the total Nurses population will be used.

\section{Sample Size Determination}

The sample size formula for estimating proportions will be used to calculate the required sample size for this study.

$\mathrm{n}=\mathrm{Z}^{2}(\mathrm{pq}) / \mathrm{d}^{2}$ (Kish formular, 1965 cited in Bamgboye, 2013)

$\mathrm{n}=$ minimum sample size

$\mathrm{d}=$ desired precision of the estimate, set at 0.05 (level of accuracy desired/sampling error (tolerance error $5 \%$ )

$z=$ standard normal deviate (set at 1.96 for $95 \%$ confidence level) $\mathrm{p}=$ the proportion of the population having the characteristic being measure $87 \%$ (cited in Arulogun et al, 2012)

$\mathrm{q}=$ the proportion of the population that does not have the characteristics $(1-p)$

$\mathrm{p}=$ prevalence of awareness of cervical cancer screening among female Nurses in Nnamdi Azikwe University Teaching Hospital, Nnewi, Nigeria $=87$ 
Therefore, $\mathrm{p}$ is 0.87

$\mathrm{q}=1-0.87=0.13$

Substituting for the values in the formula,

$\mathrm{n}=1.962 \times 0.87 \times 0.13 /(0.05)^{2}$

$\mathrm{n}=3.8416 \times 0.87 \times 0.13 / 0.0025=173.79$

$\mathrm{n}=173.79$

Estimated Sample size $=180$.

$\cdot 10 \%$ non-respondent $=1-10 / 100=0.9($ used for pilot study $=20)$

\section{Inclusion Criteria}

All the Nurses that volunteer to participate in Adeoyo Maternity Teaching Hospital, Yemetu, Ibadan.

\section{Ethical Consideration}

Confidentiality of Data: All data obtained will be kept confidential. Respondents participating and responses will be kept confidential. Their names will not be required or linked to any information obtained.

Ethical approval was sought and obtained with approved reference number AD/13/479/906 through the Oyo state Ethical Review Committee Ministry of Health Secretariat, Ibadan. The researcher visited the selected units of the hospital to serve the questionnaire personally to nurses willing to participate in the study. The nurses filled the questionnaire in their different units during the morning, afternoon and night shift overlap time.

The responses were collected on the sport, to prevent contamination and missing questionnaire. This took about four weeks, for the researcher to administer and collect the questionnaire to obtain information from the nurses.

\section{Results}

A total of 180 questionnaires administered and retrieved from the nurses however only 177 (98\%) met criteria for analysis. Hence, the respondent rate was $98.0 \%$.

\section{Age Distribution of Respondents}

The age of the respondent ranged from 23 to 59 years; the median age \pm standard deviation was $40 \pm 9.5$ years.

\section{Discussion}

\section{The Socio - Demographic Data of Respondents}

The age group of respondents ranges between 23 - 59 years Table 1 with the mean of 39.99 , ethnic group reveals that just two ethnic group of Nurses are available in the research setting the Igbo $6(3.4 \%)$ and the Yoruba 171 (96.6\%). Table 1 also shows the marital status of the respondents are in 3 categories never married $12(6.8 \%)$, married $157(88.7 \%)$ and widowed 8 (4.5\%). Table 1 shows that $158(89.3 \%)$ are Christian and $19(10.7 \%)$ are Muslims.

Table 1. Showing the Socio-demographic characteristics of respondents.

\begin{tabular}{|c|c|c|c|c|}
\hline $\mathrm{S} / \mathrm{N}$ & Variables & Options & Frequency $\mathrm{N}=177$ & Percentage $\%$ \\
\hline \multirow{4}{*}{1} & \multirow{4}{*}{ Age group } & 23-29 years & 24 & 13.6 \\
\hline & & $30-39$ years & 60 & 33.9 \\
\hline & & $40-49$ years & 54 & 30.5 \\
\hline & & $50-59$ years & 39 & 22.0 \\
\hline \multirow{2}{*}{2} & \multirow{2}{*}{ Ethnic group } & Igbo & 6 & 3.4 \\
\hline & & Yoruba & 171 & 96.6 \\
\hline \multirow{3}{*}{3} & \multirow{3}{*}{ Marital status } & Never married & 12 & 6.8 \\
\hline & & Married & 157 & 88.7 \\
\hline & & Widowed & 8 & 4.5 \\
\hline \multirow{2}{*}{4} & \multirow{2}{*}{ Religion } & Christianity & 158 & 89.3 \\
\hline & & Islam & 19 & 10.7 \\
\hline \multirow{4}{*}{5} & \multirow{4}{*}{ Educational status } & $\mathrm{RN}$ & 19 & 10.7 \\
\hline & & $\mathrm{RN} / \mathrm{RM}$ & 136 & 76.8 \\
\hline & & B.Sc. nursing & 16 & 9.0 \\
\hline & & MSc. & 6 & 3.4 \\
\hline \multirow{7}{*}{6} & \multirow{6}{*}{ Professional cadres } & NO I & 17 & 9.6 \\
\hline & & NO II & 44 & 24.9 \\
\hline & & $\mathrm{SNO}$ & 22 & 12.4 \\
\hline & & $\mathrm{PNO}$ & 52 & 29.4 \\
\hline & & $\mathrm{CNO}$ & 41 & 23.2 \\
\hline & & $\mathrm{ACNO}$ & 1 & 0.6 \\
\hline & Total & & 180 & $100 \%$ \\
\hline
\end{tabular}


Figure 1. Distribution of respondent definition of cervical cancer.

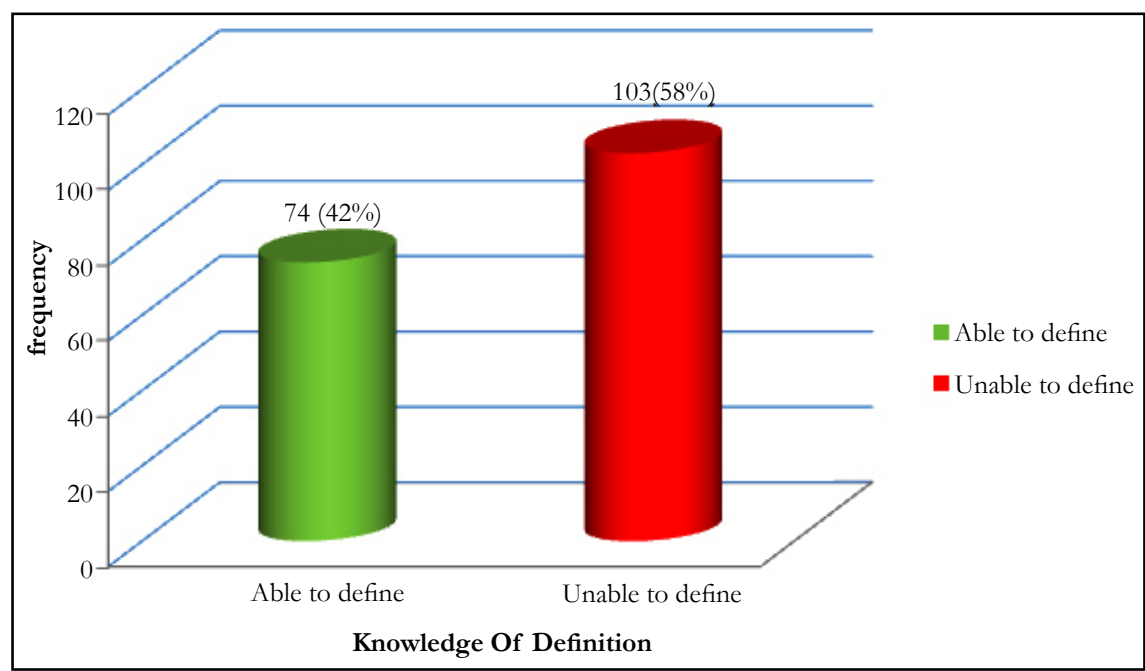

Table 2 - Research question: What are the factors affecting utilization of cervical cancer screening among Nurses in Adeoyo Maternity Teaching Hospital?

\begin{tabular}{|c|c|c|c|c|c|c|}
\hline $\mathbf{S} / \mathbf{N}$ & Statement & Strongly Agree & Agree & Undecided & Disagree & Strongly Disagree \\
\hline 1 & $\begin{array}{l}\text { I am afraid of cervical cancer } \\
\text { screening procedures pain }\end{array}$ & $14(7.9 \%)$ & $33(18.6 \%)$ & $29(16.4 \%)$ & $72(40.7 \%)$ & $29(16.4 \%)$ \\
\hline 2 & $\begin{array}{c}\text { Body exposure for CCS is } \\
\text { embarrassing }\end{array}$ & $11(6.2 \%)$ & $31(17.5 \%)$ & $10(5.6 \%)$ & $82(46.3 \%)$ & $43(24.3 \%)$ \\
\hline 3 & CCS is expensive & $16(9.0 \%)$ & $42(23.7 \%)$ & $25(14.1 \%)$ & $71(40.1 \%)$ & $23(13.0 \%)$ \\
\hline 4 & $\begin{array}{l}\text { I am healthy I cannot have } \\
\text { cervical cancer }\end{array}$ & $8(4.5 \%)$ & $20(11.3 \%)$ & $9(5.1 \%)$ & $84(47.5 \%)$ & $56(31.6 \%)$ \\
\hline 5 & $\begin{array}{l}\text { There is inadequate } \\
\text { awareness on CCS }\end{array}$ & $31(17.5 \%)$ & $72(40.7 \%)$ & $11(6.2 \%)$ & $44(24.9 \%)$ & $19(10.7 \%)$ \\
\hline 6 & CCS is not time consuming & $31(17.5 \%)$ & $84(47.5 \%)$ & $30(16.9 \%)$ & $26(14.7 \%)$ & $6(3.4 \%)$ \\
\hline 7 & CCS is not accessible & $18(10.2 \%)$ & $44(24.9 \%)$ & $16(9.0 \%)$ & $80(45.2 \%)$ & $19(10.7 \%)$ \\
\hline 8 & $\begin{array}{c}\text { My husband did not release } \\
\text { me to go for CCS }\end{array}$ & $4(2.3 \%)$ & $9(5.1 \%)$ & $16(9.0 \%)$ & $92(52.0 \%)$ & $56(31.6 \%)$ \\
\hline 9 & My culture is against CCS & $5(2.8 \%)$ & $11(6.2 \%)$ & $12(6.8 \%)$ & $89(50.3 \%)$ & $60(33.9 \%)$ \\
\hline 10 & $\begin{array}{l}\text { Do Nurse do advocacy for } \\
\text { cervical cancer screening }\end{array}$ & $23(13.0 \%)$ & $70(39.5 \%)$ & $35(19.8 \%)$ & $34(19.2 \%)$ & $15(8.5 \%)$ \\
\hline 11 & $\begin{array}{l}\text { My religion is against cervical } \\
\text { cancer screening and other } \\
\text { medical test }\end{array}$ & $5(2.8 \%)$ & $8(4.5 \%)$ & $9(5.1 \%)$ & $87(49.2 \%)$ & $68(38.4 \%)$ \\
\hline 12 & $\begin{array}{l}\text { There is no medical indica- } \\
\text { tion for me to go for cervical } \\
\text { cancer screening }\end{array}$ & $12(6.8 \%)$ & $42(23.7 \%)$ & $15(8.50 \%)$ & $61(34.50 \%)$ & $47(26.6 \%)$ \\
\hline 13 & $\begin{array}{c}\text { The money for CCS should } \\
\text { be subsidized }\end{array}$ & $50(28.2 \%)$ & $75(42.4 \%)$ & $20(11 \%)$ & $23(13 \%)$ & $9(5.1 \%)$ \\
\hline
\end{tabular}

Table 1 shows the Educational status of respondents is into four categories RN 19 (10.7\%), RN/RM 136 (76.8\%), B.Sc Nursing 16 $(9.0 \%)$ and $6(3.4 \%)$ have Master's degrees.

Research question: What are the factors affecting utilization of cervical cancer screening among Nurses in Adeoyo Maternity Teaching Hospital ?

Majority of respondents 101(57.1\%) - (Table 2) are afraid of cervical cancer screening procedure pain. This was similar to the study by Al Sairafi and Mohamed (2009) participants in a study admitted they did not go for cervical screening because of fear of pain and discomfort during the screening process. Respondents assume that this physical test will cause pain as the test kit has to be inserted into the vagina in order to take sample.

The results of the study is also in congruence with similar to other research work 125(35.3\%) which reports that body exposure for CCS is embarrassing. Al Sairafi (2009) in his study was also of the opinion that women are uncomfortable with the idea of vaginal 
Table 3. Other factors suggested by the respondents that could affect utilization of CCS negatively.

\begin{tabular}{|c|c|c|c|c|c|}
\hline \multicolumn{7}{|c|}{ Factor hindering uptake of cervical cancer screening service (i) } \\
\hline \multirow{4}{*}{} & None & Frequency & Percent \% & Valid Percent \% & Cumulative Percent \% \\
\hline \multirow{7}{*}{} & 124 & 70.1 & 70.1 & 70.1 \\
\cline { 2 - 6 } & fear/anxiety of outcome & 15 & 8.5 & 8.5 & 78.5 \\
\cline { 2 - 6 } & Superstition/belief & 1 & .6 & .6 & 79.1 \\
\cline { 2 - 6 } & Privacy problem & 2 & 1.1 & 1.1 & 80.2 \\
\cline { 2 - 6 } & Busy schedules & 16 & 9.0 & 9.0 & 89.3 \\
\cline { 2 - 6 } & pain/discomfort & 2 & 1.1 & 1.1 & 90.4 \\
\cline { 2 - 6 } & Indecision/complacency & 1 & .6 & .6 & 91.0 \\
\cline { 2 - 6 } & Ignorance & 4 & 2.3 & 2.3 & 93.2 \\
\cline { 2 - 6 } & Cost/affordability & 2 & 1.1 & 1.1 & 94.4 \\
\cline { 2 - 6 } & financial problem & 1 & .6 & .6 & 94.9 \\
\cline { 2 - 6 } & Time & 6 & 3.4 & 3.4 & 98.3 \\
\cline { 2 - 6 } & fear of unknown & 2 & 1.1 & 1.1 & 99.4 \\
\cline { 2 - 6 } & inaccessible facilities & 1 & .6 & .6 & 100.0 \\
\cline { 2 - 6 } & Total & 177 & 100.0 & 100.0 & \\
\hline
\end{tabular}

Table 4. Distribution of respondents' opinion of limiting factors for uptake of CCS.

\begin{tabular}{|c|c|c|c|c|c|}
\hline \multicolumn{6}{|c|}{ Opinion about why Nurses do not opt for cervical cancer screening } \\
\hline \multirow{4}{*}{} & Frequency & Percent \% & Valid Percent \% & Cumulative Percent \% \\
\hline \multirow{7}{*}{ Valid } & Lack of encourage women & 21 & $11.86 \%$ & $11.86 \%$ & $11.86 \%$ \\
\cline { 2 - 6 } & Poor educationon benefits & 59 & $33.33 \%$ & $33.33 \%$ & $45.19 \%$ \\
\cline { 2 - 6 } & $\begin{array}{c}\text { Health facilities should subsidize } \\
\text { cost for Nurses }\end{array}$ & 4 & $2.26 \%$ & $2.26 \%$ & $47.45 \%$ \\
\cline { 2 - 6 } & Inadequate awareness & 46 & $25.99 \%$ & $25.99 \%$ & $73.44 \%$ \\
\cline { 2 - 6 } & Poor enlightened & 4 & $2.26 \%$ & $2.26 \%$ & $75.7 \%$ \\
\cline { 2 - 6 } & Hospital based & 1 & 0.56 & 0.56 & $76.26 \%$ \\
\cline { 2 - 6 } & Inadequate knowledge & 16 & 9.04 & 9.04 & $85.3 \%$ \\
\cline { 2 - 6 } & None & 26 & $14.69 \%$ & $14.69 \%$ & $99.99 \%$ \\
\cline { 2 - 6 } & Total & 177 & 100.0 & 100.0 & \\
\hline
\end{tabular}

examination with medical practitioner, so also is the Hispanic previous study in the US reported that $31 \%$ of Hispanic women undertook the prevention of cervical cancer test admitted that the process was embarrassing, while $60 \%$ of women who did not present for screening also stated the same (Byrd, Peterson, Chavez and Heckert, 2004) [8]. Screening by male doctors affected women's decision in presenting for examination (Al-Naggar, 2012) [9]. In Australia, research carried out by Australian-Chinese community also found that patients were embarrassed during cervical screening. Researchers also indicated that the feeling of embarrassment remains even if performed by a female doctor Respondents.

$94(53.1 \%)$ respondents believed that CCS is expensive. Mupepi (2011) [3] study also viewed cost as an important issue to look into. The need for affordable health insurance among many women affected them attending clinics [3].

Table 2 also shows the respondents $140(79.1 \%)$ that believed that they are healthy and that they cannot have cervical cancer. Also $115(65 \%)$ respondents were of the view that CCS does not consumes time $99(55.9 \%)$ respondents disagrees that CCS is not accessible. $148(41.8 \%)$ respondents disagrees with not been released by their husbands to go for CCS screening. Virtually all the respondents $149(42.1 \%)$ negates their culture being against CCS. $93(10.5 \%)$ respondents agrees that nurses do advocate for cervical cancer screening. There is no medical indication to go for cervical cancer screening $108(61.1 \%)$ of the respondents disagree with this factor. $125(70.6 \%)$ of the respondents opined that CCS money should be subsidized.

Other factors suggested by respondents that can possibly affect utilization of CCS.

The respondents highlighted some other factors: in Table 3 and 4 such as $15(8.5 \%)$ of respondent viewed fear of anxiety of outcome while some $16(9.0 \%)$ of respondent viewed that women lack encouragement. Others are similar to what was highlighted in Table 5 included pain $2(1.1 \%)$, busy schedules 16 $(9.0 \%)$, ignorance cost of CCS $4(2.3 \%)$, and fear of unknown $2(1.1 \%)$. 
In Table 4 some respondents 59 (33.3\%) opined that poor response to cervical cancer treatment is possible because they have poor education about the benefits of cervical cancer screening on their health. This is in relation to the theory of care-seeking behaviour (TCSB) which uses four concepts to explain the factors leading to people's attitude towards process of seeking for health care services. The four concepts include: Pre-clinical and Sociodemographic factors, psychosocial variables, external factors and Outcome.

According to Lauver (1992) [10] the pre-clinical factors signs and symptoms such as bleeding post coitus, painful coitus (dyspareunia), vaginal discharge etc. Are seen as possible factors as well as the socio-demographic factor includes ethnicity, race, age, family size, family history, educational status and socio-economic status etc. Lauver (1992) [10] proposed that Psychosocial variants influenced people's screening behaviour to avoid illness or steps taken to get well examples of such variants includes - (a) affects, (b) beliefs, (c) norms, (d) habit (as shown in the Figure 2.15).

Under perception it is expected that if people perceived benefits to action or are threatened by ill-health or action is facilitated by reminders as suggested by some or the respondents the outcome will be to seek for intervention by visiting/reporting to the clinic for cervical screening.

\section{Conclusion and Recommendation}

This study went far to outline a lot of causes for the low utilization of cancer screening services among nurses working within this tertiary health care delivery system. The fact that the services were readily available did not mean or encourage the nurses to seek for and get tested against cervical cancer. A lot of factors were implicated which include the cost of screening, embarrassment at having to undress and even the kind of procedure needed for this screening.
The researchers within this study are of the opinion that rigorous health campaigns need to still be done as awareness and screening for this kind of cancer seems to be low. Nurses come in contact with patients on a daily basis and adequately sensitizing the nurses will go a long way in making the patients knowledgeable about this procedure and the benefits which accrue from undertaking this procedure.

\section{References}

[1]. Ahmed SA, Sabitu K, Idris SH, Ahmed R. Knowledge, attitude and practice of cervical cancer screening among market women in Zaria, Nigeria. Niger Med J. 2013 Sep;54(5):316-9. PubMed PMID: 24403709.

[2]. Al-Meer FM, Aseel MT, Al-Khalaf J, Al-Kuwari MG, Ismail MF. Knowledge, attitude and practices regarding cervical cancer and screening among women visiting primary health care in Qatar. East Mediterr Health J. 2009 Nov;17(11):855-61. PubMed PMID: 22276494.

[3]. Mupepi SC, Sampselle CM, Johnson TR. Knowledge, attitudes, and demographic factors influencing cervical cancer screening behavior of Zimbabwean women. J Womens Health (Larchmt). 2011 Jun;20(6):943-52. PubMed PMID: 21671779.

[4]. Nnodu O, Erinosho L, Jamda M, Olaniyi O, et al. Knowledge and attitudes towards cervical cancer and human papillomavirus: a Nigerian pilot study. Afr J Reprod Health. 2010 Mar;14(1):95-108. PubMed PMID: 20695142.

[5]. Aliyu SA, Sabitu K, Idris SH, Ahmed R. Knowledge, attitude and practice of cervical cancer screening among market women in Zaria, Nigeria. Niger Med J. 2013 Sep;54(5):316-9. PubMed PMID: 24403709.

[6]. Kahn JA, Goodman E, Slap GB, Huang B, Emans SJ. Intention to return for papanicolaou smears in adolescent girls and young women. Pediatrics. 2001 Aug;108(2):333-41. PubMed PMID: 11483797.

[7]. Vasconcelos CT, Bairro, RT , Ana KBP, Alexandre B. Knowledge, attitude and practice related to the pap smear test among users of a primary health unit. Rev Lat Am Enfermagem. 2011 Jan-Feb;19(1):97-105. PubMed PMID: 21412635.

[8]. Byrd TL, Peterson SK, Chavez R, Heckert A. Cervical cancer screening beliefs among young Hispanic women. Prev Med. 2004 Feb;38(2):192-7. PubMed PMID: 14715211.

[9]. Al-Naggar RA, Isa ZM. Perception and opinion of medical students about Pap smear test: a qualitative study. Asian Pac J Cancer Prev. 2010;11(2):43540. PubMed PMID: 20843130.

[10]. Lauver D. A Theory of Care-seeking Behavior. J Nurs Sch. 1992 Winter;24(4):281-7. PubMed PMID: 1452182. 